Dr Miladin Nikolić, dipl. inž. Sc Miroslav Stojanović, pukovnik, dipl. inž.

\section{KVANTIFIKACIJA OSNOVNIH KRITERIJUMA LOGISTIKE}

UDC: $355.41: 519.863$

Rezime:

U radu su analizirani, definisani i kvantifikovani efektivnost $i$ efikasnost, kao osnovni operativni kriterijumi, i troškovi, kao ekonomski kriterijum, koji služe za ocenjivanje funkcionisanja sistema uopšte i posebno sistema logistike, na osnovu kojih se može definisati niz drugih kriterijuma. Analizirani su i parametri koji utiču na ove kriterijume, kao i njihov matematički model, prilagođen za praktičnu primenu. Ukazano je na mogućnosti i ograničenja u primeni ovih kriterijuma kod organizacionih, tehničkih i bioloških sistema, kao i na mogućnosti optimizacije u izgradnji i funkcionisanju pojedinih sistema.

Ključne reči: logistika, kriterijum, efektivnost, efikasnost, troškovi, optimizacija.

\title{
QUANTIFICATION OF THE BASIC LOGISTICS CRITERIA
}

Summary:

Effectiveness and efficiency, as basic operational criteria, and costs, as basic economic criteria, are analysed, defined and quantified. These criteria are used for assessing any system funkctioning, logistics system in particular, as well as for defining other criteria. The parameters influencing these criteria are analysed as well as their mathematical model, adapted for practical implementation. Possibilities and limitations while applying these criteria in organizational, technical and biological systems have been pointedout. Possible optimizations in particular systems design and functioning have been stressed as well.

Key words: logistics, criterion, effectiveness, efficiency, costs, optimization.

\section{Uvod}

Kriterijumi u opštem smislu, a time i kriterijumi logistike, predstavljaju meru ili merila pomoću kojih se na kvantitativan ili kvalitativan način izražava stepen (nivo) osposobljenosti određenog sistema (tehničkog, biološkog, organizacionog i dr.) za izvršavanje (realizaciju) definisanih zadataka, u skladu sa postavljenim (usvojenim) ciljevima. Pri tome se, zavisno od karakteristika posmatranog siste- ma, može odrediti jedan ili (najčešće) više kriterijuma, pri čemu se teži da se kriterijumima definiše, pre svega, dobijanje kvantitativne ocene funkcionisanja (osposobljenosti) sistema.

Između ciljeva, zadataka i kriterijuma (pokazatelja funkcionisanja) posmatranog sistema postoji uzročno-posledična veza. Ciljevi sistema definišu se na osnovu opšteg (višeg) interesa. Operacionalizacija njihovog dostizanja ostvaruje se preko zadataka sistema, a vrednovanje 
rezultata funkcionisanja sistema vrši se pomoću kriterijuma sistema. Zavisno od postignutih rezultata, preko „signala povratne veze (sprege)" aktiviraju se odgovarajuće akcije koje sugerišu da u sistemu ništa ne treba menjati ili da se preispitaju i eventualno redefinišu ciljevi i/ili zadaci. U složenim organizacionim sistemima, ciljevi sistema se raščlanjuju na potciljeve, koji takođe mogu imati svoje potciljeve za koje se definišu odgovarajući zadaci, i tako redom sve dok se ne dođe do elementarnih ciljeva i zadataka (ciljevi i zadaci koji se odnose na osnovne - elementarne organizaciono-tehnološke strukture). Na blok-šemi ,drveta ciljeva i zadataka“" posmatranog sistema, kvadratima ili pravougaonicima prikazuju se ciljevi, a strelicama, koje spajaju više sa nižim ciljevima, označavaju se zadaci, čijom se realizacijom ostvaruju dati ciljevi. Ispod ciljeva najnižeg nivoa prikazuju se parametri i kriterijumi sistema.

Strogo posmatrano, moglo bi se reći da se pod kriterijumom sistema posmatra takva kvalitativna ili kvantitativna (numerička - brojna) karakteristika koja određuje stepen (nivo) osposobljenosti posmatranog sistema za izvršenje (realizaciju) određenog pred njim postavljenog zadatka, uz korišćenje (utrošak) određenih resursa. Pošto numeričke vrednosti kriterijuma predstavljaju realne brojeve, može se govoriti o preslikavanju skupa procesa funkcionisanja sistema na skup realnih brojeva unutar intervala vrednosti kriterijuma. Na taj način svaki definisani kriterijum može se smatrati zadatom funkcijom na skupu procesa funkcionisanja posmatranog sistema.

Opšta ocena funkcionisanja sistema može se dobiti pomoću dve grupe gene- ralizovanih kriterijuma - operativnih i ekonomskih. Pomoću operativnih kriterijuma (kriterijuma operativnosti) ceni se nivo (stepen) osposobljenosti sistema za realizaciju zadataka, odnosno nivo realizacije zadataka, a pomoću ekonomskih kriterijuma (kriterijuma ekonomičnosti) dobija se odgovor na pitanje po kojoj se ceni (troškovima ili utrošku resursa) realizuju usvojeni (postavljeni) zadaci.

Kvantitativni izrazi generalizovanih kriterijuma ocene funkcionisanja sistema treba da zadovolje sledeće zahteve:

- da numerički i na najopštiji način karakterišu stepen (nivo) realizacije zadatka;

- da su jednostavni za izvođenje proračuna (za primenu i dobijanje vrednosti kriterijuma);

- da ih karakteriše mogućnost normiranja, tj. da imaju malu disperziju.

\section{Operativni kriterijumi}

U svojstvu operativnih kriterijuma, za ocenu funkcionisanja logističkih sistema koriste se kriterijumi efektivnosti ${ }^{1} \mathrm{i}$ kriterijumi efikasnosti ${ }^{2}$, kao i niz drugih kriterijuma izvedenih iz ova dva osnovna.

Efektivnost sistema odnosi se na domen strategijskog (strateškog) planiranja, koje je usmereno na utvrđivanje razvoja logističkog sistema, dok je efikasnost sistema vezana za domen operativnog pla-

Efektivnost (lat. effectivus) označava učinak, uspešnost, korist, a usmerena je na strateško planiranje, realizaciju ciljeva razvoja sistema i ostvarivanje kvaliteta proizvoda ili usluga koje tržište zahteva, odnosno prihvata.

${ }^{2}$ Efikasnost (lat. efficacitus) označava uspešnost sistema i odnosi se na operativne zadatke u toku funkcionisanja (eksploatacije) sistema. Sadrži pojmove, odnosno principe racionalnosti, ekonomičnosti i rentabilnosti. Može se posmatrati na različite načine, ali je zajednički da se pod efikasnošću podrazumeva sposobnost da se ostvare postavljeni ciljevi ili zadaci sa datim resursima. 
niranja, koje je orijentisano na planiranje realizacije operativnih - tekućih zadataka.

Ako se za efektivnost može reći da je funkcija kvaliteta proizvoda ili usluga, onda je efikasnost funkcija organizacije $u$ kojoj se efektivnost realizuje. Zbog toga, malo je koristi ako je određena organizacija efikasna ukoliko ne daje adekvatne rezultate, to jest nema smisla da organizacija bude efikasna ukoliko je odabran pogrešan cilj. Znači da efektivnost predstavlja osnovu za postizanje uspeha, a efikasnost minimalan uslov za opstanak, kada je uspeh već postignut. Drugačije rečeno - dok efektivnost znači raditi prave stvari, efikasnost znači raditi stvari na pravi način. Biti efektivan i efikasan znači raditi prave stvari na pravi način. Uvažavajući navedeno, u logistici savremenih oružanih snaga prednost se daje efektivnosti, a zatim efikasnosti.

Efektivnost sistema (za tehničke sisteme - tehnička efektivnost) i troškovi životnog veka sistema vezani su za idejno rešavanje (dizajniranje), projektovanje i izgradnju organizacionih sistema, odnosno proizvodnju ili nabavku određenih tehničkih sistema (sredstava NVO), a efikasnost i troškovi funkcionisanja sistema predstavljaju elemente za vrednovanje postojećeg (realnog) sistema.

Efektivnost sistema $\mathrm{E}(\mathrm{t})$ definiše se, u matematičkom smislu, kao verovatnoća da će sistem u određenom vremenu biti $u$ radu, uz propisani režim upotrebe i uz provođenje propisanih mera održavanja (provođenje propisanih preventivno-korektivnih programa održavanja), a izražava se kao proizvod pouzdanosti $\mathrm{P}(\mathrm{t})$, funkcionalne podobnosti (podobnosti za funkcionalnu upotrebu) FP(t) i raspoloži- vosti (gotovosti) za namensku upotrebu $R(t), t j:$

$E(t)=P(t) \cdot F P(t) \cdot R(t)$

S obzirom na to da svaka od komponenti efektivnosti može poprimiti vrednost $\mathrm{u}$ intervalu od 0 do 1 , iste vrednosti može poprimiti i efektivnost sistema, s tim da će njena vrednost uvek biti jednaka ili manja od najmanje vrednosti pojedinih komponenti efektivnosti. Komponente efektivnosti, kao i ukupna efektivnost sistema, razmatraju se i usvajaju još u fazi razvoja sistema, pri čemu se analiziraju njihove vrednosti za celokupni (programirani) životni vek sistema.

Prve dve komponente efektivnosti (pouzdanost i funkcionalna podobnost) predstavljaju lična (inherentna) svojstva sistema, i sastavni su element njegovog ustrojstva (konstrukcije). Pouzdanost, po definiciji, kao verovatnoća rada bez otkaza u toku vremena, ima statističku vrednost, a veličine koje se analiziraju i posmatraju su slučajnog karaktera. Ona predstavlja najvažniji element kvaliteta proizvoda i usluga. Zbog toga u poslednjih tridesetak godina ona dobija istaknuti značaj kao primenjena naučna grana koja se direktno oslanja na teoriju verovatnoće i matematičke statistike. Potreba za poznavanjem konkretnih parametara pouzdanosti procesa, usluga, tehničkih proizvoda i njihovih komponenata sve je veća, a pouzdanost se sve više ugrađuje u osnovne deklarisane karakteristike proizvođača i zahteve korisnika. Funkcionalna podobnost predstavlja skladno ,dizajnirani odnos" taktičko-tehničkih karakteristika (zahteva naručioca i tehničko-tehnoloških mogućnosti) posmatranog sistema, koje omogućavaju da sistem na opti- 
malan način realizuje svoju osnovnu funkciju, uz minimalan utrošak resursa. Pouzdanost i funkcionalna podobnost razmatraju se, usvajaju i u sistem ugrađuju u toku njegovog razvoja. U toku funkcionisanja (eksploatacije) sistema menjaju se vrednosti ove dve komponente, pa se njihovo očuvanje u granicama usvojenih vrednosti vrši po odgovarajućim programima preventivnog i korektivnog održavanja. Zbog toga se za praktične potrebe proračunavanja efektivnosti sistema tokom njegovog životnog veka može uzeti da su vrednosti pouzdanosti i funkcionalne podobnosti poznate kao konstrukcione konstante, $\mathrm{tj}$. da je $\mathrm{P}(\mathrm{t})=\mathrm{K}_{1}$, a $\mathrm{FP}(\mathrm{t})=\mathrm{K}_{2}$, odnosno da je $\mathrm{K}_{1} \cdot \mathrm{K}_{2}=\mathrm{K}$. U tom slučaju efektivnost sistema $\mathrm{u}$ realnim uslovima funkcionisanja (eksploatacije) definiše se izrazom:

$\mathrm{E}(\mathrm{t})=\mathrm{K}_{1} \cdot \mathrm{K}_{2} \cdot \mathrm{R}(\mathrm{t})=\mathrm{K} \cdot \mathrm{R}(\mathrm{t})$

Raspoloživost (gotovost) sistema za namensku upotrebu, kao treća komponenta efektivnosti sistema je složena jer njena vrednost istovremeno zavisi od usvojenih konstrukcionih rešenja (svojstava) sistema (koja pored pouzdanosti obuhvataju i pogodnost za održavanje, kao element funkcionalne podobnosti), od karakteristika funkcionisanja sistema i od postojeće organizacije održavanja.

Raspoloživost (gotovost) sistema definiše se, u matematičkom smislu, kao verovatnoća da će sistem u razmatranom periodu vremena $(\mathrm{T})$ biti raspoloživ za namensku upotrebu, u realnim uslovima eksploatacije, uz sprovođenje planiranih aktivnosti održavanja i podrške održavanju. Izražava se kao odnos vremena kada je sistem raspoloživ za namensku upotrebu i ukupno razmatranog vremena $(\mathrm{T})$, tj.
$\mathrm{R}(\mathrm{t})=\mathrm{t}_{\mathrm{r}} /\left(\mathrm{t}_{\mathrm{r}}+\mathrm{t}_{\mathrm{o}}\right)=\mathrm{t}_{\mathrm{r}} / \mathrm{T}$

gde je:

$\mathrm{t}_{\mathrm{r}}$ - vreme kada je sistem raspoloživ za upotrebu;

$\mathrm{t}_{\mathrm{o}}$ - vreme kada je sistem izvan upotrebe;

$\mathrm{T}$ - ukupno razmatrano vreme.

Vreme neraspoloživosti sistema za upotrebu $\left(\mathrm{t}_{\mathrm{o}}\right)$, predstavlja komponentu raspoloživosti sistema na koju utiču tri različita vremenska parametra, $i$ to:

$t_{o}=t_{\text {adm }}+t_{\text {log }}+t_{\text {od }}$

gde je:

$\mathrm{t}_{\mathrm{adm}}$ - vreme neraspoloživosti sistema zbog administrativnog čekanja, na koje utiču razlozi izvan sistema održavanja (informisanje o zastoju sistema i druge administrativne mere);

$t_{\log }$ - vreme neraspoloživosti sistema na koje utiču logistički razlozi (nedostatak rezervnih delova i čekanje na njihovu nabavku, neraspolaganje adekvatnom strukturom i brojem specijalizovane radne snage za održavanje, neraspolaganje adekvatnom opremom i prostorom za održavanje i drugo);

$t_{\text {od }}$ - efektivno vreme za održavanje, koje zavisi od pogodnosti za održavanje razmatranog sistema.

Prve dve komponente vremena neraspoloživosti sistema odnose se na karakteristike organizacije u kojoj se odvija održavanje, a treća komponenta predstavlja lično svojstvo, koje karakteriše konstrukcija sistema. Zbog toga se vreme održavanja razmatra kao konstanta, jer je za najveći broj tehničkih sistema normirano posebnim propisima (u Vojsci je normiranje vremena održavanja regulisano Uputstvima TU-V, tj. jedinstvenim normativima za održavanje tehničkih sredstava). 
Može se uočiti da raspoloživost (gotovost) sistema istovremeno zavisi od njegovih konstrukcionih svojstava i od karakteristika organizacije u kojoj funkcioniše i realizuje se njegovo održavanje.

Efektivnost sistema detaljno se analizira i proračunava u fazi razvoja sistema, kada se usvajaju pojedine komponente efektivnosti u odnosu na njenu željenu, odnosno moguću (projektovanu) vrednost, a što se usklađuje sa visinom troškova koji „pokrivaju“ efektivnost sistema u njegovom životnom veku. Pri tome moraju se činiti određeni kompromisi između želja (vrednosti efektivnosti) i mogućnosti (visine troškova za dostizanje željene efektivnosti), s obzirom na to da se ta dva zahteva ne mogu istovremeno optimizirati (ne može se maksimizirati efektivnost uz istovremenu minimizaciju troškova životnog veka sistema). Moguće je da se za definisanu (usvojenu) efektivnost minimiziraju troškovi životnog veka sistema ili da se za unapred definisane (ograničene) troškove životnog veka traži maksimalna efektivnost sistema, što je u praksi češći slučaj. Rešavanje ovog problema detaljnije je prikazano u ${ }^{\mathrm{a}} 4^{\mathrm{o}}$.

U realnim uslovima funkcionisanja (eksploatacije) sistema značajna je analiza njegove efektivnosti, posebno sa stanovišta raspoloživosti u razmatranom periodu mira ili rata (vrši se a priori ili a posteriori, zavisno od cilja i mogućnosti realizacije analize), što je za sistem komandovanja veoma značajno. U tom slučaju za vrednosti pouzdanosti i funkcionalne podobnosti sistema uzimaju se njihove konstrukcione vrednosti (kao konstante sistema), a raspoloživost se izračunava na osnovu snimljenih parametara za određeni period (a posteriori proračun), ili na osnovu parametara dobijenih simulacijom procesa funkcionisanja posmatranog sistema (a priori proračun). Proračun efektivnosti na ovaj način vrši se prema izrazima (2), (3) i (4).

Sve što je do sada rečeno o efektivnosti odnosi se na pojedine elemente sistema, odnosno na pojedina tehnička sredstva. Međutim, u realnim uslovima funkcionisanja (eksploatacije) sistema neophodno je odrediti efektivnost za pojedine grupe istovetnih elemenata sistema, odnosno za pojedine grupe istovetnih tehničkih sredstava (određene vrste vazduhoplova, brodova, tenkova, transportnih vozila, artiljerijskog naoružanja i drugih istorodnih sredstava NVO) ili za pojedine grupe sistema sa različitim elementima ili sredstvima koji poseduju određene zajedničke karakteristike (svi tipovi borbene avijacije, sva borbena vozila, motorna vozila točkaši, celokupno artiljerijsko ili streljačko naoružanje, određene vrste sredstava veze, i dr.). Tada proračun efektivnosti određene grupe treba da obuhvati sve elemente (sredstva) iz sastava te grupe. Međutim, to je teško izvodljivo zbog poteškoća oko utvrđivanja pojedinih parametara efektivnosti za pojedine grupe (posebno ako se sastoje od različitih elemenata, odnosno sredstava), pa se zbog praktičnih razloga može proračunavati samo raspoloživost, dok pouzdanost i funkcionalnu podobnost treba razmatrati kao konstrukcione karakteristike, odnosno kao unapred zadate konstante (ekspertski procenjene za grupe sa različitim elementima), koje ulaze u proračun efektivnosti.

Dakle, kada se, radi pojednostavljenja proračuna, uzimaju u obzir konstrukcione (procenjene) vrednosti parametara 
pouzdanosti i funkcionalne podobnosti, za $j$ posmatranih elemenata, odnosno sredstava $(j=1,2, \ldots n)$, koja pripadaju itoj grupi $(i=1,2, \ldots \mathrm{m})$, raspoloživost te grupe elemenata (sredstava) u posmatranom periodu (T) bila bi:

$$
\begin{aligned}
& \operatorname{Ri}(t)=\sum_{j=i}^{n} t r i j /\left(\sum_{j=i}^{n} t r i j+\sum_{j=i}^{n} t o i j\right)= \\
& =\sum_{j=i}^{n} t r i j / n_{i} \cdot T
\end{aligned}
$$

Istovremeno, efektivnost posmatrane grupe elemenata (sredstava) sistema računala bi se prema izrazu:

$$
E i(t)=\left(K_{1} K_{2}\right) i \cdot R i(t)=K_{i} R i(t)
$$

Teoretski, moguće je izračunavanje vrednosti efektivnosti sistema i za više grupa elemenata (sredstava), odnosno za sistem u celini, u kojem se pojedine grupe bitno razlikuju po pitanju konstrukcionih karakteristika. Međutim, praktično nije moguća realizacija takvog zahteva, jer je vrlo komplikovano izračunavanje pouzdanosti i funkcionalne podobnosti za grupe sa različitim elementima (sredstvima). Umesto toga, za potrebe sistema komandovanja moguće je proračunavanje približne vrednosti efektivnosti sistema, s tim da se za pouzdanost i funkcionalnu podobnost uzmu vrednosti koeficijenata $\left(K_{1} i K_{2}\right)_{i}$, odnosno vrednost koeficijenta $K_{i}$ za pojedine grupe elemenata (sredstava) sistema. Pri tome, ako nije moguće da se na drugi način odrede vrednosti navedenih koeficijenata, moguće je da se ekspertski jedna grupa elemenata (sredstava) proglasi za etalon, i da joj se dodeli maksimalna vrednost koefi- cijenta, a ostalim grupama da se dodele relativne vrednosti koeficijenata u granicama od nule do usvojene maksimalne vrednosti. U tom slučaju, za m grupa elemenata (sredstava) posmatranog sistema, za razmatrani period vremena $(\mathrm{T})$, raspoloživost (gotovost) bi se računala pomoću izraza:

$$
\begin{aligned}
& \operatorname{Rsis}(t)=\operatorname{Rij}(t)=\sum_{i=1}^{m} \sum_{j=1}^{n} \text { trij } / \\
& /\left(\sum_{i=1}^{m} \sum_{j=1}^{n} \operatorname{trij}+\sum_{i=1}^{n} \sum_{j=1}^{m} t o i j\right)= \\
& =\sum_{i=1}^{m} \sum_{j=1}^{n} \operatorname{trij} / \sum_{i=1}^{m} n_{1} \cdot T
\end{aligned}
$$

Približna vrednost efektivnosti sistema računala bi se pomoću sledećeg izraza:

$$
E_{s i s}(t)=\prod_{i=1}^{m} K_{i} \cdot R_{s i s}(t)
$$

Efektivnost sistema, dobijena prema izrazu (8), naziva se logistička efektivnost i predstavlja osnovni (najznačajniji) kriterijum za ocenjivanje funkcionisanja logističke organizacije, jer pokazuje sa kojom verovatnoćom će sistem funkcionisati bez otkaza u razmatranom periodu. Ovom kriterijumu daje se prednost u odnosu na kriterijum efikasnosti. Umesto logističke efektivnosti može se izračunati samo raspoloživost sistema prema izrazu (7), koja se naziva logistička raspoloživost i koja pokazuje prosečnu raspoloživost (gotovost) sistema za namensku upotrebu u razmatranom periodu, a što je za sistem komandovanja od posebnog značaja. 
Efektivnost sistema kao, najznačajniji logistički kriterijum, analizira se i računa u toku razvoja (dizajniranja i projektovanja) sistema s ciljem da se optimiziraju troškovi životnog veka sistema, a u toku kojeg se analizira i računa za određeni period funkcionisanja (eksploatacije), kako bi se za taj period realnije sagledale vrednosti efektivnosti i logističke obaveze. S obzirom na poteškoće koje se javljaju pri utvrđivanju osnovnih parametara efektivnosti, možda je interesantnije (svakako jednostavnije) da se u periodu funkcionisanja (eksploatacije) sistema analizira i računa samo raspoloživost sistema, s obzirom na to da se na njenu vrednost $\mathrm{u}$ tom periodu može uticati, a da se na pouzdanost i funkcionalnu podobnost ne može uticati (jer su njihova svojstva definisana još u toku razvoja sistema i ugrađena u njegovu konstrukciju, programima održavanja se drže u dozvoljenim granicama, a putem modifikacija i adaptacija menjaju im se konstrukciona svojstva). U realizaciji određenih istraživačkih zadataka, za dobijanje numeričkih pokazatelja za pojedine parametre efektivnosti i za efektivnost u celini, bez obzira na to da li se to radi u periodu razvoja ili funkcionisanja (eksploatacije) sistema, preporučuje se primena metoda simulacije funkcionisanja (eksploatacije) sistema, uz korišćenje savremene računarske tehnologije. Takođe, za dobijanje efektivnosti u uslovima realnog funkcionisanja sistema neophodno je raspolagati računarski sređenim podacima o parametrima efektivnosti u posmatranom periodu, koji se koriste za automatizovano proračunavanje efektivnosti prema izrazima (5-8). Primeri ovako definisane efektivnosti mogu se naći u ${ }^{\mathrm{a}}$, 4 i $9^{\circ}$.
Izloženi model za utvrđivanje efektivnosti odnosi se, pre svega, na tehničke sisteme, a može se koristiti i za organizacione sisteme. Međutim, uz odgovarajuću interpretaciju model se može primeniti i za utvrđivanje efektivnosti bioloških sistema, gde izvršnu ulogu u realizaciji određenih zadataka direktno realizuje čovek ili neka životinja. Pri tome, vrlo je bitno da se izuče i definišu odgovarajući parametri pouzdanosti i funkcionalne podobnosti (pogodnosti za realizaciju odgovarajućih zadataka), dok se parametri raspoloživosti (gotovosti) bitno ne razlikuju od odgovarajućih parametara za tehničke sisteme, s tim da parametar, ,vreme za održavanje" sistema treba zameniti parametrom ,zdravstvena podrška“ (preventivna i kurativna). Parametri pouzdanosti i funkcionalne podobnosti u vezi su sa određenim osobinama ljudskog bića, odnosno posmatrane vrste životinja: prirodne osobine (starost, fizičke dimenzije, fizička kondicija, inteligencija, karakterne crte i sl.), nivo obrazovanja, odnosno kvantum raspoloživog znanja, nivo obučenosti za namenske zadatke i dr. Za realizaciju određenih zadataka treba definisati vrednosti etalon-parametara pouzdanosti i funkcionalne podobnosti, koje treba komparirati sa parametrima odgovarajućih izvršilaca tih zadataka, na osnovu čega se mogu dobiti vrednosti pouzdanosti i funkcionalne podobnosti. Parametri raspoloživosti mogu se dobiti snimanjem funkcionisanja posmatranog biološkog sistema kroz određeno vreme, ili simulacijom procesa funkcionisanja tog sistema na elektronskom računaru. $\mathrm{Na}$ taj način moguće je istražiti efektivnost odgovarajućih bioloških struktura u realizaciji njihovih zadataka: određene medicinsko-sa- 
nitetske i veterinarske ekipe i timovi, posebno oblikovane tehničko-tehnološke strukture za obavljanje posebnih zadataka u tehničkoj, intendantskoj, saobraćajnoj, građevinskoj i drugim službama, kao i u određenim rodovima vojske. U vezi s tim može se istražiti optimizacija odnosa efektivnosti i troškova.

Efikasnost sistema E definiše se u matematičkom smislu kao odnos (količnik) između izlaza (output) i ulaza (input), tj. kao odnos proizvoda i resursa (dobiti i ulaganja, potreba i mogućnosti), odnosno efekata i sredstava, što, u suštini, predstavlja ekonomski koncept. Matematička interpretacija efikasnosti, u najopštijem obliku, glasi:

$\mathrm{E}=\mathrm{O}$ (output) / I (input)

Polazeći od opštih zahteva, najcelishodnija ocena efikasnosti u sistemu logistike može se dobiti pomoću uporedne analize dva pokazatelja kriterijuma operativne efikasnosti ${ }^{a}{ }^{\circ}$. Prvi pokazatelj operativne efikasnosti treba da karakteriše realnu (faktičku) efikasnost na osnovu ocene stanja i mogućnosti funkcija logističke podrške, a označava se sa $E f$. Može se dobiti proračunom na osnovu podataka koji karakterišu stanje potfunkcija i elemenata logistike, ili predviđanjem (prognoziranjem) njihovog stanja. Drugi pokazatelj operativne efikasnosti treba da odredi zadatu (traženu) efikasnost, koja je neophodna za realizaciju postavljenih zadataka, a označava se sa $E t$.

Operativna ocena stepena realizacije postavljenog zadatka određuje se pomoću izraza:
$\mathrm{Ef} / \mathrm{Et} \geq 1$, tj. Ef $\geq$ Et $\Rightarrow$ realizacija zadatka zadovoljava,

Ef/Et $<1$, tj. Ef $<$ Et $\Rightarrow$ realizacija zadatka ne zadovoljava.

Na taj način izražava se kvantitativan odnos između faktičke i tražene efikasnosti sistema. Pri tome, neophodno je da se pri ocenjivanju operativne efikasnosti koriste i vremenski pokazatelji (kriterijumi). U tom slučaju koriste se sledeći odnosi:

$T f / T t \leq 1, t j . T f \leq T t \Rightarrow$ zadaci se realizuju ne samo potpuno već i pravovremeno,

$T f / T t>1, t j . T f>T t \Rightarrow$ zadaci se ne izvršavaju u zadato vreme i neophodna su dodatna istraživanja radi definisanja koje zadatke treba realizovati pravovremeno, a koje ne.

Radi dobijanja što meritornije ocene za preduzimanje mera za povećanje efikasnosti sistema logistike, u skladu sa preporukama* $^{*}$ pogodno je da se u svojstvu kriterijuma (pokazatelja) efikasnosti koriste dva posebna kriterijuma - kriterijum operativne efikasnosti i kriterijum sposobnosti sistema.

Kriterijum operativne efikasnosti $E_{k}$, pokazuje koliki je doprinos k-te strukture sistema logistike u ukupno ostvarenoj efikasnosti logistike. Njegove vrednosti su u granicama od 0 do $100 \%$, a izražava se na sledeći način:

$$
E_{k}=\left\lfloor\left(E_{k}^{u}-E_{k}^{o}\right) / E_{k}^{u}\right\rfloor \cdot 100[\%]
$$

Tarakanov, Ovčarov, Tiriškin: Analitičeskie metodi isledovanija sistem. Sovjetskoe radio, Moskva, 1979. 
Kriterijum sposobnosti $U_{k}$, za k-tu strukturu sistema logistike izražava se na sledeći način:

$U_{k}=\left(E_{k}^{u}-E_{k}^{o}\right) /\left(E_{k}^{i}-E_{k}^{o}\right)$

gde je:

$E_{k}^{u}$ - vrednost kriterijuma efikasnosti logističke organizacije pri uzimanju u obzir doprinosa k-te strukture logistike;

$E_{k}^{o}-$ vrednost kriterijuma efikasnosti logističke organizacije bez uzimanja u obzir doprinosa k-te strukture logistike;

$E_{k}^{i}$ - vrednost kriterijuma efikasnosti logističke organizacije kada posmatrana k-ta struktura maksimalno realizuje zadatke koji se pred nju postavljaju.

Očigledno je da kriterijum $U_{k}$ može da poprimi vrednosti između 0 i 1 . Pri $E_{k}^{u}=E_{k}^{o} \Rightarrow U_{k}=0$, što znači da k-ta struktura ne doprinosi ukupnoj efikasnosti logističke organizacije. Obrnuto, pri $E_{k}^{u}=E_{k}^{i} \Rightarrow U_{k}=1$, što znači da posmatrana k-ta struktura zadovoljava maksimalnim zahtevima logističke organizacije.

Izrazi (9-13) mogu se podjednako koristiti za izračunavanje efikasnosti tehničkih, bioloških, organizacionih i drugih sistema.

Efikasnost sistema, kao drugi po značaju logistički kriterijum, vezan je za eksploataciju (funkcionisanje) sistema, pa samim tim zavisi od postavljene organizacije i njenih realnih mogućnosti. $U$ suštini numerička vrednost efikasnosti sistema je količnik izlaza (autputa) iz sistema i ulaza (inputa) u sistem, odnosno dobiti i ulaganja, ostvarenog i uloženog, faktičkog i traženog i sl. Takođe, za efikasnost sistema bitno je i vreme realizacije zadatka, koje treba da bude kraće ili jednako unapred određenom vremenu. Pored toga, u svojstvu kriterijuma efikasnosti sistema mogu se koristiti još dva posebna kriterijuma - kriterijum operativne efikasnosti i kriterijum sposobnosti sistema, čije vrednosti predstavljaju doprinos pojedinih elemenata sistema njegovoj ukupnoj efikasnosti. Navedeni kriterijumi efikasnosti mogu se podjednako koristiti kod tehničkih, bioloških, organizacionih i drugih sistema.

\section{Ekonomski kriterijumi}

Pokazatelji vojno-ekonomskih kriterijuma vezani su za ekonomičnost $t^{3}$ posmatranog sistema i predstavljaju određena ulaganja ( $u$ istraživanja, kadrove, infrastrukturu, opremu i sl.) i utrošak određenih resursa (novac, radna snaga, materijalna sredstva, energija i dr.) u funkciji realizacije definisanih zadataka u toku pojedinih faza životnog veka posmatranog sistema (koncepcija, odnosno dizajniranje sistema, razvoj, izgradnja - proizvodnja, odnosno nabavka, eksploatacija i održavanje i „umiranje“, odnosno povlačenje iz upotrebe i otuđivanje iz vojske). To znači da se preko ovih kriterijuma mogu izraziti ukupne potrebe za određenim resursima za životni vek u celini, ili za pojedine njegove faze posmatranog sistema.

Racionalna upotreba, odnosno efikasno korišćenje ograničenih resursa, mora se vršiti primenom određenih organizacionih i ekonomskih principa. Tome se može obezbediti maksimiziranje učinka logističke podrške na borbenu sposobnost, odnosno na namensku ulogu vojske.

Ekonomičnost predstavlja meru kvaliteta sistema sa stanovišta ulaganja, odnosno troškova ulaganja (ulazni faktori) i vrednosti dobijene u sistemu (izlaz iz sistema). 
Optimizacija kriterijuma logistike

$\mathrm{Za}$ razliku od efektivnosti i efikasnosti, za koje se želi da poprime maksimalne vrednosti, teži se da ekonomski pokazatelji (kriterijumi) poprime minimalne vrednosti.

Istovremeno se žele postići maksimalni efekti uz minimalan utrošak resursa, što u matematičkom smislu nije moguće. S obzirom na to da je nemoguće istovremeno optimizirati ove dve veličine, moguće je da se jedna od njih optimizira, a da se druga fiksira na neku vrednost. Moguće je postići maksimalne efekte za zadate troškove (ograničeni utrošak resursa) ili minimizirati troškove (utrošak resursa) za unapred zadate efekte. Zbog toga se u praktičnoj realizaciji (izgradnji i funkcionisanju) određenih sistema pribegava izboru kompromisnih rešenja. Danas postoji veliki broj usavršenih metoda, prilagođenih za primenu pomoću elektronskog računara ${ }^{\mathrm{a}} 5^{\mathrm{o}}$.

$\mathrm{Na}$ osnovu strukturno-funkcionalnog modela određenog logističkog sistema, i odabranih kriterijuma za ocenu efektivnosti i efikasnosti, mogu se formirati dve operativne i matematičke postavke zadatka.

Prva operativna postavka zadatka ima za cilj dobijanje takve strukture logističkog sistema koja će omogućavati da se zadaci uspešno izvršavaju pri minimalnom utrošku resursa (minimalni troškovi). Koristi se u uslovima kada resursi nisu ograničeni ili kada ih ima toliko da u potpunosti zadovoljavaju potrebe.

Druga operativna postavka zadatka podrazumeva da se snage i sredstva koriste tako da efekti budu maksimalni, odnosno da se maksimalno zadovolje potre- be korisnika sredstava ili usluga, tj. teži se da $\mathrm{Ef} / \mathrm{Et} \Rightarrow$ maksimum. Primenjuje se u uslovima postojanja ograničenih resursa za realizaciju zadataka, sa težnjom da se potpuno ili maksimalno zadovolje potrebe onih korisnika koji imaju najvažniju ulogu u realizaciji zadataka.

Dakle, nije moguća istovremena maksimizacija efekata i minimizacija utroška resursa, već je moguće da se jedna od te dve veličine minimizira ili maksimizira, a druga „fiksira“. Naime, za definisane efekte potrebno je minimizirati utrošak resursa ili za date resurse tražiti maksimalne efekte.

U savremenim uslovima, primenom neke od numeričkih metoda i računarske tehnologije (hardver/softver), moguće je doći do vrlo povoljnih kompromisnih rešenja u izboru odnosa efekti - troškovi za pojedine faze, „života“ ili za životni vek u celini određenih logističkih sistema. U svim vojskama u miru se više ekonomiše, jer se raspolaže ograničenim (fiksiranim) finansijskim sredstvima, pa se pribegava maksimizacija učinaka (efekata). Nasuprot tome, u ratu se definiše (fiksira) realizacija određenih ciljeva, pa je moguće optimizirati (minimizirati) troškove, odnosno utrošak raspoloživih resursa za realizaciju tih ciljeva.

\section{Zaključak}

Za objektivno ocenjivanje bilo kog sistema, pa tako i logističkih sistema, nužno je postojanje dve grupe kriterijuma, od kojih jedni služe za merenje efekata (operativni kriterijumi), a drugi za registraciju utrošaka resursa (ekonomski kriterijumi). Kao dva najznačajnija operativna kriterijuma, u radu su obrađeni efektivnost i efikasnost, za koje 
su date definicije, relevantni parametri i matematičke interpretacije. Za izgradnju i funkcionisanje sistema vezan je utrošak odgovarajućih resursa koji se definišu kao ekonomski kriterijumi (utrošak novca, repromaterijala i energije, korišćenje kadrova, prostora, alata, opreme, infrastrukture i dr.).

S obzirom na to da je za ove dve grupe kriterijuma predznak rasta suprotan (težnja je da efekti rastu, a da troškovi padaju) nije moguća istovremena optimizacija obe grupe kriterijuma. Moguće je da se efekti ,fiksiraju“, a troškovi optimiziraju (minimiziraju), ili da se troškovi ograniče, a efekti optimiziraju (maksimiziraju), što je u praksi češći slučaj, posebno u miru. Time je stvorena realna mogućnost za dobijanje kvantitativne ocene o izgrađenosti i funkcionisanju istraživanog sistema, odnosno odgovora na pitanje - da li sistem ,radi prave stvari na pravi način".

\section{Literatura:}

${ }^{a} 1^{\circ}$ Eklz. Logistika u nacionalnoj odbrani. Beograd, VIZ, 1964. ${ }^{\mathrm{a}} 2^{\circ}$ Goluško. I. M., Varlamov, N. V.: Osnovi modelarovanija i avtomatizacii upravljenija tilom. Moskva, Voenizdat, 1982

a ${ }^{\circ}$ NIR u tehničkoj služi. Usavršavanje sistema održavanja TMS u KoV OS i snabdevanja rezervnim delovima: definiranje $\mathrm{i}$ izbor kriterija, ograničenja $\mathrm{i}$ pokazatelja valjanosti sistema održavanja TMS KoV OS i snabdevanja r/d u miru i ratu (elaborat). VVTŠ KoV JNA, 1985.

${ }^{a} 4^{\circ}$ Nikolić, M.: Efikasnost funkcionisanja sistema tehničkog obezbeđenja združenih taktičkih jedinica u oružanoj borbi (doktorska disertacija). Zagreb, VVTŠ KoV JNA, 1989.

${ }^{a} 5^{\circ}$ Nikolić, I., Borović, S.: Višekriterijumska optimizacija (metode, primena u logistici, softver). CVŠ VJ, Beograd, 1996.

${ }^{\mathrm{a}} 6^{\mathrm{o}}$ Nikolić, M.: Logistička podrška savremenih oružanih snaga (studija). SP GŠ VJ, 1997.

${ }^{a} 7^{\circ}$ Tomanović, R., Nikolić, M.: Komparativna analiza pozadinskog obezbeđenja i logističke podrške savremenih oružanih snaga (studija). SP GŠ VJ, 1998.

${ }^{\text {a }}{ }^{\circ}$ Fokusirana logistika (Prevod smernica fokusirane logistike SAD do 2010. god.). SP GŠ VJ, 1998.

${ }^{a} 9^{\circ}$ Grupa autora: Varijantna rešenja organizacije održavanja materijalnih sredstava u Vojsci Jugoslavije na logističkim osnovama (projektni zadatak), KTOb VTA VJ, 2000.

${ }^{a} 10^{\circ}$ Ilić, R.: Vojnoekonomska moć odbrane SR Jugoslavije. Centar ŠONID, ŠNO, 2000.

${ }^{a} 11^{\circ}$ Mišković, V., Stanojević, P.: Kriterijumi za ocenu varijantnih rešenja organizacije logističke podrške - pozadinskog obezbeđenja. U: VTG, 2001, 1. 